\title{
Osteoporosis in rheumatoid arthritis: safety of low dose corticosteroids
}

\author{
P N SAMBROOK, ${ }^{1} \mathrm{~J}$ A EISMAN,${ }^{1}$ M G YEATES,${ }^{2} \mathrm{~N}$ A POCOCK, ${ }^{1}$ S EBERL,${ }^{2}$ \\ AND G D CHAMPION
}

From the ${ }^{1}$ Garvan Institute of Medical Research, the ${ }^{2}$ Department of Nuclear Medicine, and the ${ }^{3}$ Department of Rheumatology, St Vincent's Hospital, Sydney

SUMMARY Fear of inducing generalised osteoporosis is one reason why corticosteroids are withheld in patients with rheumatoid arthritis (RA). No studies, however, have directly measured bone density in such patients at clinically relevant sites. To assess this risk we measured bone mineral density in the lumbar spine and femoral neck by dual photon absorptiometry in 84 patients with RA, 44 of whom had been treated with low dose prednis(ol)one (mean dose $\pm \mathrm{SE} 8 \cdot 0 \pm 0.5 \mathrm{mg} /$ day; mean duration of treatment $89.6 \pm 12.0$ months). There were significant reductions in bone mineral density in patients treated with corticosteroids (lumbar $9.6 \%, \mathrm{p}<0.001$; femoral $12.2 \%, \mathrm{p}<0.001)$ and in those who had not received corticosteroids (lumbar 6.9\%, p <0.01; femoral 8.9\%, p<0.001), but the differences between the two groups were not significant. We conclude on the basis of these studies that low dose oral corticosteroids do not increase the risk of generalised osteoporosis in patients with rheumatoid arthritis.

Key words: dual photon absorptiometry.

In rheumatoid arthritis (RA), oral corticosteroids are usually reserved for patients with severe disease refractory to other drugs. Although effective in suppressing synovitis, concern about side effects in the long term, such as osteoporosis, have limited their use in uncomplicated RA. ${ }^{1}$ Some studies have shown that corticosteroids have a significant role in osteoporosis in $\mathrm{RA}^{2-7}$ while others have failed to confirm an increased incidence of osteoporosis. ${ }^{8-11}$ The reasons for these discrepancies probably relate to differences in the methods used to assess osteoporosis and differences in the patient groups studied, especially with respect to severity of RA and corticosteroid dose.

Several recent studies have suggested that low dose corticosteroids may be relatively safe in RA with regard to the risk of developing osteoporosis. ${ }^{10} 12$ Assessment of this risk requires accurate quantitative studies of bone mass at clinically relevant sites. Previous studies of osteoporosis in steroid treated RA patients have employed either

Accepted for publication 8 May 1986.

Correspondence to Dr P N Sambrook, Garvan Institute of Medical Research, St Vincent's Hospital, Darlinghurst, NSW 2010, Australia. insensitive radiological methods to assess axial bone mass $^{2} 3810$ or newer techniques applied to measure peripheral skeletal mass ${ }^{4} 7^{11}$ or total body calcium (TBCa). ${ }^{579}$ Studies that examine only peripheral sites may reflect localised (juxta-articular) rather than generalised osteoporosis. Similarly, measurements of TBCa do not allow determination of the relative contributions of localised and generalised bone loss to any changes observed. In this study we have used dual photon absorptiometry to measure bone density at the fracture prone sites of the lumbar spine and femoral neck in women with RA treated either with or without low dose corticosteroids.

\section{Patients and methods}

Female patients consecutively seen in the Department of Rheumatology of St Vincent's Hospital who had definite or classical RA ${ }^{13}$ were asked to participate. Informed consent was obtained from each patient and the study received Ethical Committee approval. To assess disease severity we recorded each patient's functional class and anatomical grade. ${ }^{4}$ Patients receiving calcium supplements $(n=17)$ or sex hormones $(n=10)$ were not excluded. 
Bone mineral density (BMD, $\mathrm{g} / \mathrm{cm}^{2}$ ) in the lumbar spine and femoral neck was measured with a Lunar DP-3 dual photon absorptiometer (Lunar Radiation Corporation, Madison, Wisconsin, USA) employing a gadolinium-153 source $(44 \mathrm{keV}, 100$ $\mathrm{keV}, 40 \mathrm{GBq})$. Scans were made of three lumbar vertebrae and the right femoral neck and BMD derived by dividing the bone mineral content of each region by the projected bone area. The radiation dose to the skin with this method is less than $100 \mu \mathrm{Gy}$ and to the ovaries less than $200 \mu \mathrm{Gy}$. The coefficient of variation of repeat measurements in postmenopausal women using this method is $2.6 \%{ }^{15} x$ Rays of the thoracolumbar spine were performed in patients older than 40 years to detect vertebral fractures and osteoarthritis. In patients with severe osteoarthritis of the lumbar spine, lumbar BMD values were not included in the analysis.

BMD values were expressed as percentages relative to the mean values obtained from a linear regression of BMD against age in normal women (Pocock N A, Eisman J A, Yeates M G, et al, in preparation). This control group comprised 69 subjects with no known history of bone disease, all of whom gave informed consent (mean age 49.1 years, range 20-75 years). Unpaired $t$ tests and $\chi^{2}$ tests were used to compare groups. Simple and multiple regression analysis was also used in the evaluation of data.
Table 1 Clinical details of patients

\begin{tabular}{lll}
\hline & $\begin{array}{l}R A \text { not receiving } \\
\text { steroids }(n=40)\end{array}$ & $\begin{array}{l}\text { RA receiving } \\
\text { steroids }(n=44)\end{array}$ \\
\hline Age (years) & $55 \cdot 8(14 \cdot 2)^{*}$ & $56 \cdot 2(13 \cdot 4)$ \\
Number premenopausal & 11 & 9 \\
Number postmenopausal & 29 & 35 \\
Disease duration (years) & $11 \cdot 8(8 \cdot 9)$ & $14 \cdot 7(8 \cdot 5)$ \\
Functional class & 15 & 7 \\
I & 22 & 27 \\
II & 3 & 10 \\
III & - & - \\
IV & 7 & 2 \\
Anatomical grade & 15 & 11 \\
I & 18 & 31 \\
II & - & - \\
III & & \\
IV & &
\end{tabular}

${ }^{*}$ Values are mean $(\mathrm{SD})$.

\section{Results}

Eighty four patients with RA were studied, of whom 44 were receiving prednis(ol)one. Clinical details of the two patient groups are shown in Table 1. Patients on corticosteroids had a longer mean disease duration, but this difference was not statistically significant. Disease severity assessed by functional class and anatomical grade was more advanced in patients on corticosteroids, and these differences were significant $\left(p<0 \cdot 05, \chi^{2}\right)$. The mean

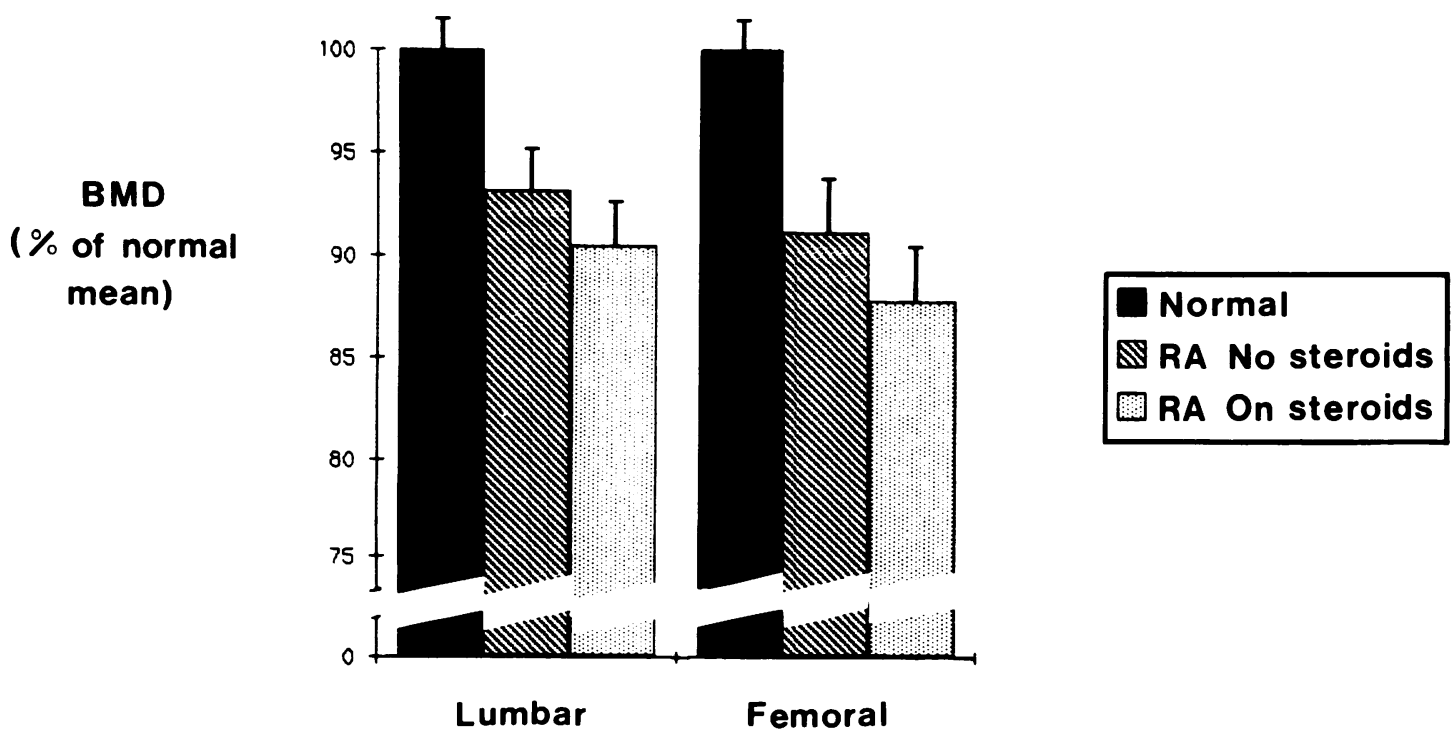

Fig. 1 Bone mineral density corrected for age and expressed as a percentage of values seen in normal women (mean $\pm S E$ ). 
Table 2 Effect of menopausal status

\begin{tabular}{lll}
\hline & $\begin{array}{l}R A \text { not receiving } \\
\text { steroids }\end{array}$ & $\begin{array}{l}R A \text { receiving } \\
\text { steroids }\end{array}$ \\
\hline $\begin{array}{l}\text { Premenopausal } \\
\text { Lumbar BMD }\end{array}$ & $95 \cdot 0 \pm 2 \cdot 4$ & $94 \cdot 9 \pm 6 \cdot 4$ \\
$\begin{array}{l}\text { Femoral BMD } \\
\text { Postmenopausal }\end{array}$ & $92 \cdot 6 \pm 4 \cdot 4$ & $88 \cdot 6 \pm 8 \cdot 8$ \\
$\quad$ Lumbar BMD & $91 \cdot 9 \pm 2 \cdot 5$ & $88 \cdot 5 \pm 2 \cdot 1$ \\
Femoral BMD & $89 \cdot 8 \pm 2 \cdot 8$ & $82 \cdot 4 \pm 2 \cdot 5$ \\
\hline
\end{tabular}

BMD corrected for age and expressed as a percentage of value seen in normal women (mean $\pm \mathrm{SE}$ ).

dose of prednis(ol)one taken was $8.0 \mathrm{mg} /$ day (range $2 \cdot 5-16 \cdot 8)$, and the mean duration of treatment was 89.6 months (range $1 \cdot 5-300 \cdot 0$ ).

The BMD in the lumbar spine and femoral neck of each patient group relative to normal women are shown in Fig. 1. In patients not treated with corticosteroids the reduction was $6.9 \%$ in the lumbar spine $(p<0.01)$ and $8.9 \%$ in the femoral neck $(p<0.001)$. In patients treated with corticosteroids the reduction was $9.6 \%$ in the lumbar spine $(p<0.001)$ and $12.2 \%$ in the femoral neck $(\mathrm{p}<0.001)$. Although mean BMD values for corticosteroid treated patients were lower than for patients not receiving steroids, this difference was not significant. (Beta error considerations indicate a certainty of having not missed a difference of $10 \%$ in BMD between the groups of $90 \%(1-\beta)$.) To investigate whether the lower values for steroid treated patients were due to the longer disease duration and more advanced disease seen in this group, a regression of BMD against disease duration, functional class, and anatomical grade was performed in patients not treated with corticosteroids, and this equation was then used to predict BMD in patients treated with steroids. The predicted values were $6.9 \%$ in the lumbar spine and $11.7 \%$ in the femoral neck, suggesting that the lower values seen in the steroid group may in part be accounted for by their longer disease duration and increased disease severity.

Separate analysis of each group in pre- and postmenopausal categories failed to show any influence of corticosteroids on BMD values in relation to menopausal status (Table 2). In patients on corticosteroids there was no significant correlation between BMD and average daily dose of prednisone, duration of therapy, or cumulative dose.

In patients receiving corticosteroids seven out of 37 had radiological evidence of vertebral fractures, while in patients who had not received steroids three out of 36 had vertebral fractures. This difference was not significant.
Discussion

In the present study we have examined bone mineral density at the clinically important sites of the lumbar $\stackrel{?}{\rightarrow}$ spine and femoral neck in patients with RA. We have examined only women with RA, but previous workers have suggested the risk of osteoporosis is greater in women treated with corticosteroids than $\underset{\Omega}{\triangle}$ in men. ${ }^{2} 510$ The findings do not suggest that low dose corticosteroids result in generalised osteoporosis in RA. Other mechanisms such as disuse osteoporosis related to loss of mobility may be more important in this respect and indeed increased mobility after suppression of synovitis by corticosteroids may be of positive benefit for the skeleton in some patients. ${ }^{16}$

The role of corticosteroids in causing generalised osteoporosis in RA has been controversial. Differences in the methods used to assess osteoporosis explain some of these discrepancies. Studies that have assessed osteoporosis by grading standard $x$ rays $^{2} 8$ underestimate the degree of osteoporosis since osteopenia is not evident radiologically until $30-50 \%$ of bone mineral has been lost. ${ }^{77}$

More sophisticated techniques such as single photon absorptiometry have been applied to meas sure radial bone mass in RA. Mueller and Juris found a significant reduction in radial mid-sha bone mass in RA but only in patients who had received corticosteroids. ${ }^{4}$ D'Angelo et al found radial bone mass was significantly reduced in patients with RA compared with normals but could show no difference between patients who had received steroids and those who had not. ${ }^{11}$ Als et al found distal radial bone mass was reduced in all patients with RA compared with normals, but the reduction was greater in premenopausal women treated with corticosteroids than in those not receiving them. ${ }^{7}$ In contrast, de Deuxchaisnes et al found no reduction in radial mid-shaft bone mass in premenopausal women receiving low dose corticosteroids but a significant reduction in postmenopausal women. ${ }^{6}$ Our results do not support the suggestion of Als $\mathrm{et} \mathrm{al}^{7}$ that premenopausal RA women are more at risk of osteoporosis from corticosteroids, but the number of premenopausal women in our study was relatively small. Studies that have measured only peripheral sites such as the radius, often close to joints involved by RA, may reflect localised rather than generalised osteoporosis.

Another approach has been the measurement of TBCa or total body bone mineral in patients with RA. Some studies have shown reductions in TBCa in patients treated with corticosteroids, ${ }^{57}$ but others have failed to confirm this. ${ }^{9}$ As such techniques 
treat the skeleton as a unit it is not possible to determine the relative contributions of localised and generalised bone loss to the changes observed.

The use of oral corticosteroids in low dosage in RA is undergoing a reappraisal. ${ }^{1} 12161819$ Our study suggests that low dose oral corticosteroids do not result in significant axial bone loss in RA, and fear of inducing osteoporosis should not influence the decision to use these agents.

The authors wish to thank Drs C D Browne, M L Cohen, and R O Day for allowing them to study their patients and Ms Anne Duncan and Ms Janet Wilks for expert technical assistance.

\section{References}

1 Myles A. Corticosteroid treatment in rheumatoid arthritis. $\mathrm{Br} \mathrm{J}$ Rheumatol 1985: 24: 125-7.

2 Saville P D, Kharmosh O. Osteoporosis of rheumatoid arthritis: influence of age, sex and corticosteroids. Arthritis Rheum 1967; 10: $423-30$.

3 Buchanan W W, Samuels B M, Jasani M K. et al. Do oral corticosteroids cause osteoporosis in rheumatoid arthritis? Ann Rheum Dis 1970; 29: 560-1.

4 Mueller M N, Jurist J M. Skeletal status in rheumatoid arthritis. Arthritis Rheum 1973; 16: 66-70.

5 Reid D M, Kennedy N S J. Smith M A. Tothill P, Nuki G. Total body calcium in rheumatoid arthritis: effects of disease activity and corticosteroid treatment. $\mathrm{Br}$ Med $J$ 1982; 285: 330-2.

6 de Deuxchaisnes C N, Devogelaer J P, Esselinckx W, et al. The effect of low dosage glucocorticoids on bone mass in rheumatoid arthritis: a cross-sectional and a longitudinal study using single photon absorptiometry. In: Avioli L V, Gennari C, Imbibo B, eds. Advances in experimental medicine and biology. New York: Plenum, 1984; 171: 209-39.
7 Als OS, Gotredsen A. Christiansen C. The effect of glucocorticoids on bone mass in rheumatoid arthritis patients. Arthritis Rheum 1985; 28: 369-75.

8 McConkey M, Fraser G M. Bligh A S. Osteoporosis and purpura in rheumatoid arthritis: prevalence and relation to treatment with corticosteroids. $Q J$ Med 1962; 31: 419-27.

9 Kennedy A C. Boddy K. Williams E D. et al. Whole body elemental composition during drug treatment of rheumatoid arthritis: a preliminary study. Ann Rheum Dis 1979: 38: 137-40.

10 Hajiroussou V J, Webley D M. Prolonged low-dose corticosteroid therapy and osteoporosis in rheumatoid arthritis. Ann Rheum Dis 1984; 43: 24-7.

11 D'Angelo A. Fabris A. Sartori L, et al. Mineral metabolism and bone mineral content in rheumatoid arthritis. Effect of corticosteroids. Clin Exp Rheumatol 1985; 3: 143-6.

12 Guyatt G H, Webber C E. Mewa A A, Sackett D L. Determining causation - a case study: adrenocorticosteroids and osteoporosis. J Chron Dis 1984; 37: 343-52.

13 Ropes M W, Bennett G A, Cobb S, Jacox R. Jessar A R. Proposed diagnostic criteria for rheumatoid arthritis. Ann Rheum Dis 1959; 18: 49.

14 Steinbrocker O, Traeger C H, Batterman R C. Therapeutic criteria in rheumatoid arthritis. JAMA 1949; 140: 659-62.

15 Krolner B, Pors Nielsen S. Measurement of bone mineral content (BMC) of the lumbar spine. 1. Theory and application of a new two dimensional dual photon attenuation method. Scand J Clin Lab Invest 1980; 40: 653-63.

16 Million R. Kellgren J H, Poole P. Jayson M I V. Long-term study of management of rheumatoid arthritis. Lancet 1984; i: 812-6.

17 Meema H E. Cortical bone atrophy and osteoporosis as a manifestation of aging. AJR 1963; 89: 1287-95.

18 Masi A T. Low-dose glucocorticoid therapy in rheumatoid arthritis (RA): transitional or selected add-on therapy? $J$ Rheumatol 1983; 10: 675-8.

19 Butler R C, Goddard D H. Controversy in the treatment of rheumatoid arthritis. Lancet 1984; ii: 278-9. 